Vol. 3 No. 1, 2015

\title{
ANALISIS TINGKAT KEPUASAN WISATAWAN DOMESTIK TERHADAP KUALITAS PELAYANAN TICKETING PADA PT. INDONESIA AIR ASIA CABANG DENPASAR
}

\author{
Putu Ayu Nugraheni \\ I Made Sendra \\ I GPB. Sasrawan Mananda \\ Email : nugraheni_ayu@ymail.com \\ PS. S1 Industri Perjalanan Wisata \\ Fakultas Pariwisata UNUD
}

\section{ABSTRACT}

Tourists are given to choose many airlines which have their excellence. Tourist want to choose the cheaper price, but on the other hand they also want to have convenience on their travelling. Therefore, the competition among low cost carrier airlines caused many airlines begin to increase their facilities for their passangers such as, PT. Indonesia Air Asia.

Datas in this research were collected by observation, interview, questionnaire and literature. Using accidental sampling with 65 domestic tourist respondences. While quality service dimentions are using tangibles, empathy, responsiveness, reliability and assurance.

The result shows that factor of ticketing staffs performance in handling complaint is major priority with correspond to level $51,06 \%$, the ability of ticketing staffs to give response to tourist needs become the second priority with correspond to level 54,38\%. And the third priority is ability of ticketing staffs to give clear information with correspond to level 55,47\%. Those factors have the lowest correspond level and have to take into priority for improvement process. While the factor which has the highest rate is the grooming performance of ticketing staffs with correspond to level $98,16 \%$.

\section{Keywords: Service Quality and Satisfaction of Travelers.}

\section{PENDAHULUAN}

Dalam dunia pariwisata saat ini transportasi udara adalah suatu andalan karena kecepatannya, efisiensinya dan jangkauan tujuannya yang luas. Saat ini kebutuhan para konsumen dalam menggunakan jasa transportasi udara semakin meningkat dikarenakan semakin berkembangnya sektor industri penerbangan. Wisatawan dihadapkan pada banyak pilihan maskapai penerbangan yang mempunyai keunggulan masing-masing.

$$
\text { Persaingan antara maskapai }
$$

penerbangan berbiaya tinggi dengan penerbangan low cost carrier semakin ketat. Low cost carrier (LCC) merupakan penerbangan berbiaya rendah, dimana harga tiketnya dapat dijangkau oleh masyarakat luas. Beberapa orang tentu berfikir bahwa penerbangan berbiaya rendah tidak menjamin kualitas pelayanan yang baik.

Hasil wawancara dengan salah satu staff ticketing Air Asia menerangkan bahwa ada beberapa keluhan dari wisatawan domestik terhadap pelayanan yang diberikan oleh ticketing, diantaranya lamban dalam menangani complaint dan kurang tanggap terhadap apa yang diinginkan wisatawan. Selain itu wisatawan mengeluh karena staff ticketing kurang ramah dalam melayani wisatawan pada saat reservasi tiket.

\section{TINJAUAN PUSTAKA}

Kotler dalam Rangkuti (2003:23) menjelaskan kepuasan pelanggan adalah perasaan senang atau kecewa seseorang sebagai hasil dari perbandingan antara prestasi 
atau produk yang dirasakan dan yang diharapkannya.

Menurut Zulian Yamit (2005:78) kepuasan konsumen merupakan evaluasi purna beli atau hasil evaluasi setelah membandingkan apa yang dirasakan dengan harapannya. Dalam konsep kepuasan konsumen, adapun elemen yang mempengaruhi yaitu:

1. Kinerja adalah persepsi konsumen terhadap apa yang ia terima setelah mengkonsumsi produk.

2. Harapan adalah pikiran konsumen tentang apa yang akan diterimanya apabila ia mengkonsumsi produk.

3. Derajat kepentingan adalah perasaan wisatawan terhadap derajat kepentingan setiap karakteristik kualitas pelayanan.

Wisatawan adalah seseorang yang melakukan suatu perjalanan wisata meninggalkan tempat asalnya dengan jangka waktu sekurang-kurangnya 24 jam. (Suwantoro, 1997:4). Damardjati (2001:42) mendefinisikan wisatawan domestik yaitu wisatawan dalam negeri yang menyelenggarakan perjalanannya ke tempattempat tujuan wisata yang semuanya masih berada dalam batas-batas wilayahnya sendiri.

Kualitas jasa atau kualitas pelayanan yang mendefinisikan sebagai kondisi dinamis yang berhubungan dengan produk, jasa, sumber daya manusia, proses dan lingkungan yang memenuhi atau melebihi harapan. (Tjiptono, 2005 : 110). Kotler dalam Majid (2009:46), menyatakan terdapat lima kriteria penentu kualitas jasa, yaitu:

1. Tangible (keandalan), yaitu berupa fasilitas dan perlengkapan karyawan.

2. Empathy (empati), yaitu memberikan perhatian kepada pelanggan dan memahami apa yang diinginkan pelanggan.

3. Reliability (keandalan), yaitu kemampuan perusahaan untuk melakukan pelayanan sesuai yang dijanjikan dengan segera, akurat dan memuaskan.
4. Responsiveness (ketanggapan), yaitu kemampuan perusahaan untuk menangani pelanggan dengan baik.

5. Assurance (keyakinan/jaminan), yaitu sikap sopan terhadap pelanggan dalam memberikan pelayanan serta dapat dipercaya agar pelanggan bebas dari resiko.

Ticketing yang dimaksud disini adalah penjualan tiket kepada calon wisatawan dan kemudian tiket tersebut diproses dan diberikan kepada wisatawan sebagai dokumen perjalanan. (Kamus Oxford, 2009:1604)

\section{METODE PENELITIAN}

Sampel pada penelitian ini dapat ditentukan dengan cara mengalikan 5 dengan jumlah pertanyaan (indikator) dalam kuisioner. Dalam kuisioner penelitian ini terdapat 13 indikator, sehingga jumlah responden yang didapat yaitu sebanyak 65 responden, yang diperoleh dari mengalikan 5 variabel dengan 13 indikator. Responden didapatkan dengan menggunakan purposive sampling, yaitu pemilihan sampel berdasarka pada ciri atau sifat yang dipandang mempunyai sangkut paut atau kriteria. Untuk menganalisis tingkat kepuasan wisatawan terhadap kualitas pelayanan pada PT. Indonesia Air asia cabang Denpasar menggunakan pengukuran skala likert. Jawaban atas pertanyaan yang diberikan, mempunyai skor tertinggi lima (5) dan nilai terendah satu (1).

Dalam analisis yang menyangkut 13 faktor pelayanan pada Air Asia Denpasar ini, terdapat dua buah variabel yang diwakili oleh huruf $\mathrm{X}$ merupakan tingkat kinerja perusahaan yang memberikan kepuasan pada wisatawan, sedangkan huruf $\mathrm{Y}$ merupakan tingkat kepentingan wisatawan. Dari perbandingan kedua variabel ini dapat diperoleh tingkat kesesuaian responden.

\section{PEMBAHASAN}

Berdasarkan penelitian dengan 65 responden, di dapat rata-rata penilaian kinerja dan penilaian kepentingan serta tingkat kesesuaian, seperti pada tabel dibawah ini. 


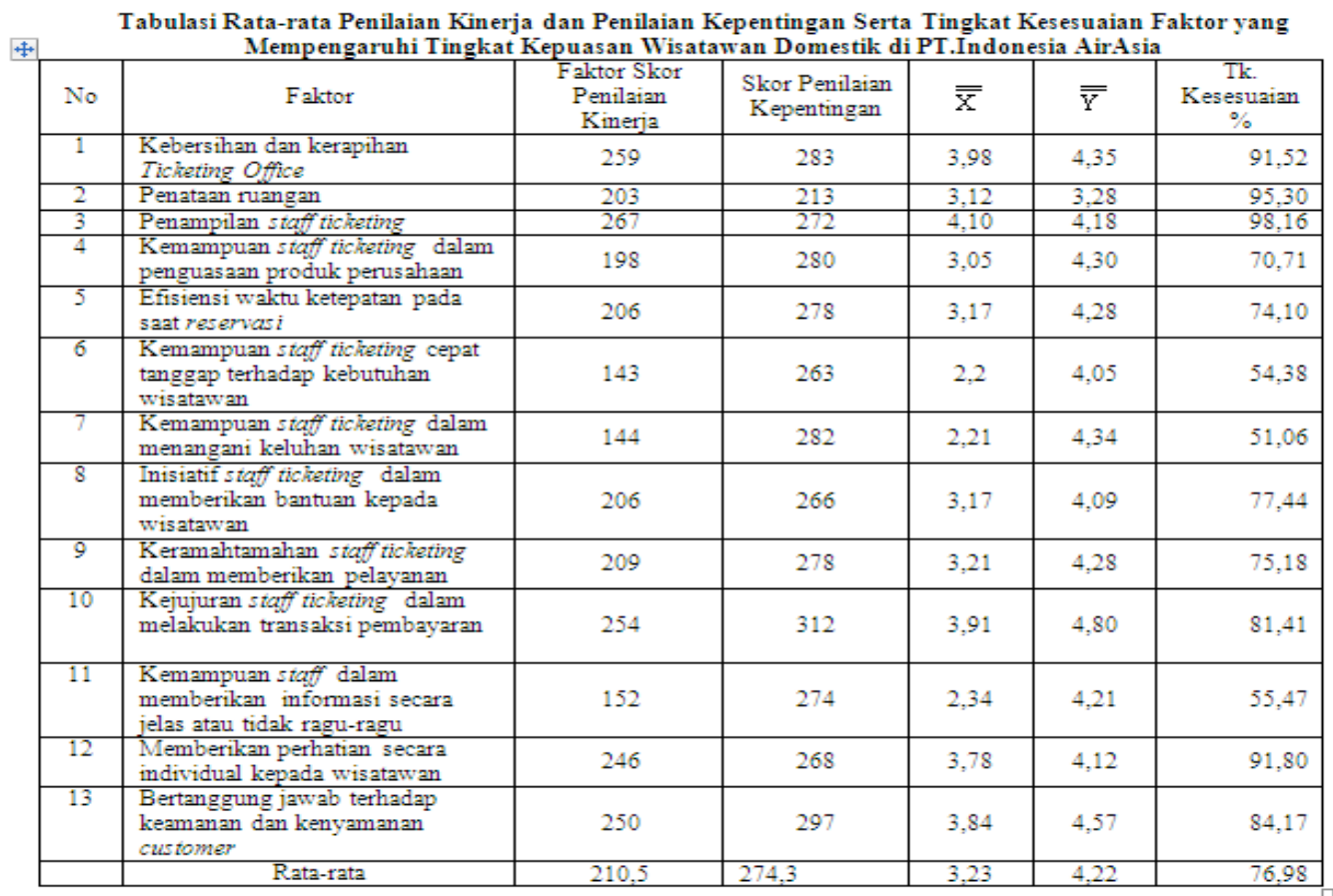

Perhitungan rata-rata dari rata-rata tingkat kinerja seluruh faktor yang mempengaruhi kepuasan konsumen pada PT. Indonesia Airasia Cabang Denpasar adalah :

$$
\begin{aligned}
\overline{\overline{\mathrm{X}}} & =\frac{\sum_{i}^{\mathrm{n}}=1 \overline{\mathrm{X}}}{\mathrm{K}} \\
\overline{\overline{\mathrm{X}}} & =\frac{3,98+3,12+4,10+3,05+3,17+2,2+2,21+3,17+3,21+3,91+2,34+3,78+3,84}{13} \\
& =3,23
\end{aligned}
$$

Perhitungan rata-rata dari rata-rata tingkat kepentingan seluruh faktor yang

mempengaruhi kepuasan wisatawan pada PT Indonesia Airasia Cabang Denpasar adalah :

$$
\begin{aligned}
\overline{\bar{Y}} & =\frac{\sum_{i}^{n}=1 \bar{Y}}{K} \\
\overline{\bar{Y}} & =\frac{4,35+3,28+4,18+4,30+4,28+4,05+4,34+4,09+4,28+4,80+4,21+4,12+4,57}{13} \\
& =4,21
\end{aligned}
$$

Berdasarkan hasil perhitungan tersebut di atas dapat menentukan garis yang berpotongan tegak lurus, yang pada akhirnya membagi diagram kartesius menjadi empat bagian. Selanjutnya faktor dari tingkat kinerja dan tingkat kepentingan dimasukkan ke dalam diagram Kartesius. Adapun interpretasi dari diagram kartesius dapat dijelaskan sebagai berikut :

1. Kaudran A

Faktor yang menempati kuadran ini merupakan faktor-faktor yang dirasa penting dan merupakan prioritas utama oleh wisatawan namun perusahaan belum melaksanakan dengan baik sehingga faktor yang berada pada kuadran ini adalah, kemampuan staff ticketing dalam penguasaan produk perusahaan (faktor 4), efisiensi waktu dan ketepatan pada saat reservasi (faktor 5), kemampuan staff ticketing dalam menangani keluhan wisatawan (faktor 7), keramahtamahan staff ticketing dalam memberikan pelayanan (faktor 9), dan kemampuan staff dalam memberikan informasi secara jelas atau tidak ragu-ragu (faktor 11).

2. Kaudran B

Wisatawan merasa bahwa faktor-faktor yang berada pada posisi ini sangat penting dan nelaksanaannva sudah dilakukan 
perusahaan perlu mempertahankan prestasi. Adapun faktor-faktor yang berada pada kuadran ini antara lain, kebersihan dan kerapihan Ticketing Office (faktor 1), kejujuran staff ticketing dalam melakukan transaksi pembayaran (faktor 10) bertanggung jawab terhadap keamanan dan kenyamanan customer (faktor 13).

3. Kuadran C

Kuadran ini merupakan prtioritas rendah, dimana atribut-atribut produk kurang berpengaruh bagi konsumen. Faktor yang berada pada posisi ini yaitu, penataan ruangan (faktor 2), kemampuan staff ticketing cepat tanggap terhadap kebutuhan wisatawan (faktor 6) dan inisiatif staff ticketing dalam memberikan bantuan kepada wisatawan (faktor 8).
4. Kuadran D

Posisi ini menunjukkan atribut-atribut produk tidak dianggap pentik bagi konsumen, namun perusahaan melaksanakannya dengan baik sehingga di anggap berlebihan bagi konsumen. Faktor yang terdapat dalam kuadran ini menunjukkan bahwa wisatawan menilai faktor ini kurang penting namun dalam pelaksanaannya sangat memuaskan sehingga wisatawan menganggap ini berlebihan. Adapun faktor-faktor yang berada pada kuadran ini antara lain, penampilan staff ticketing (faktor 3) dan memberikan perhatian secara individual kepada wisatawan (faktor 12).

Diagram Kartesius Mengenai Kepuasan Wisatawan

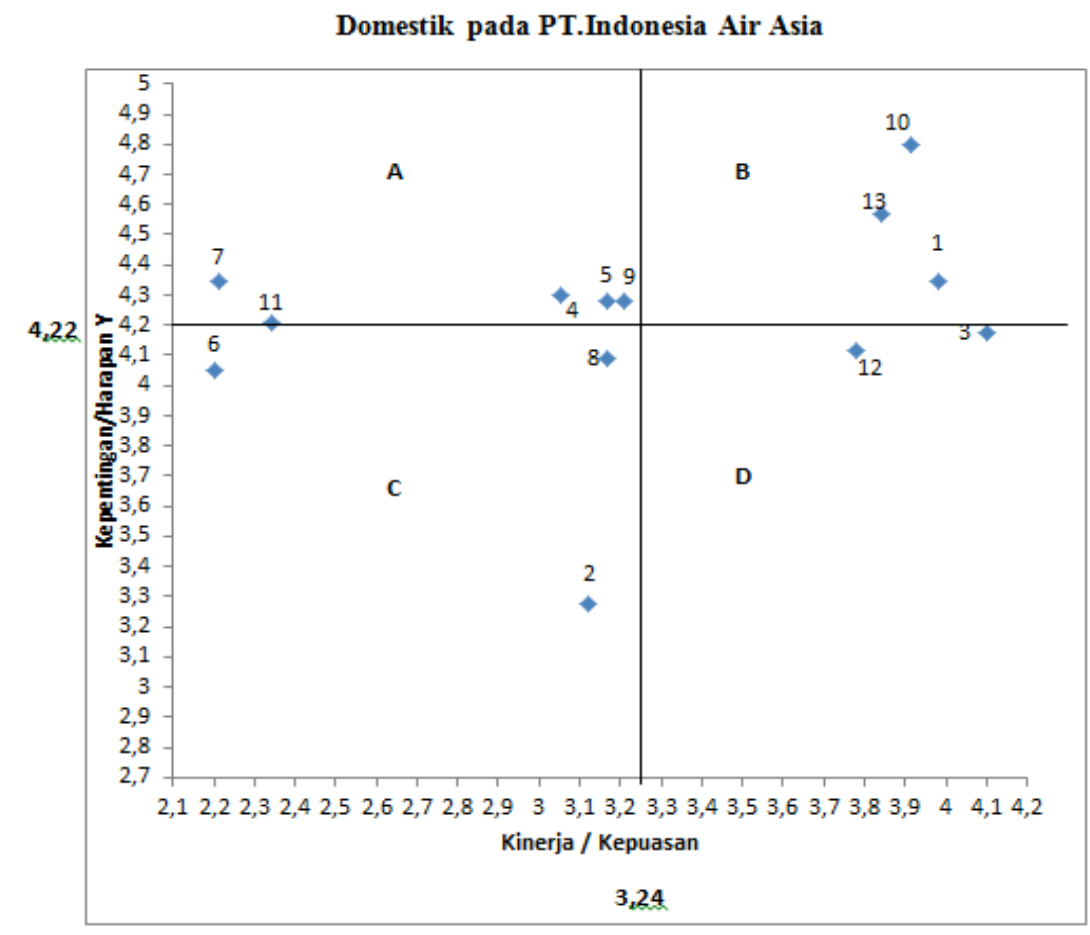

\section{SIMPULAN DAN SARAN}

Simpulan

Berdasarkan hasil dan pembahasan yang telah dipaparkan, dalam kaitannya mengenai tingkat kepuasan wisatawan domestik terhadap kualitas pelayanan ticketing pada PT. AirAsia Cabang Denpasar dengan menggunakan analisis tingkat kepentingan kinerja, maka dapat disimpulkan hal-hal sebagai berikut:

1 Nimanci buslitas nolorianon rono karena pelaksanaannya dilakukan dengan baik yaitu, tangibles, reliability dan empathy. Dimensi tangibles meliputi faktor, (1) penampilan staff ticketing dengan tingkat kesesuaian $98,16 \%$, (2) penataan ruang dengan tingkat kesesuaian 95,30\%, dan (3) kebersihan dan kerapihan ticketing office dengan tingkat kesesuaian $91,52 \%$. Reliability meliputi faktor (1) aficianci wobtu dan batanatan nada cast 
$74,10 \%$ dan (2) kemampuan staff ticketing dalam penguasaan produk perusahaan dengan tingkat kesesuaian $70,71 \%$.

2. Faktor dari dimensi kualitas pelayanan yang memiliki tingkat kesesuaian paling kecil, merupakan faktor dengan prioritas utama, artinya faktor tersebut perlu mendapatkan pembenahan dalam pelaksanaannya agar wisatawan merasa puas. Beberapa faktor tersebut adalah, (1) kemampuan staff ticketing dalam menangani keluhan wisatawan dengan tingkat kesesuaian 51,06\%,

kemampuan staff ticketing cepat tanggap terhadap kebutuhan wisatawan dengan tingkat kesesuaian $54,38 \%$ dan kemampuan staff ticketing dalam memberikan informasi secara jelas atau tidak ragu-ragu dengan tingkat kesesuaian $55,47 \%$.

\section{Saran}

Berdasarkan kesimpulan disampaikan beberapa saran yang dapat dipertimbangkan oleh manajemen PT. Indonesia Air Asia Cabang Denpasar antara lain :

1. Staff ticketing dalam menangani keluhan wisatawan agar lebih ditingkatkan karena staff kurang memperhatikan atau berangkapan keluhan dari wisatawan kurang penting. Selain itu staff ticketing diharapkan memberikan informasi dengan alasan yang jelas atau tidak ragu-ragu apabila terjadi cancel flight agar wisatawan dapat mengerti dengan jelas dan memakluminya.

2. Kemampuan staff ticketing cepat tanggap terhadap kebutuhan wisatawan agar ditingkatkan, dengan demikian wisatawan akan merasa puas karena para staff telah memahami dan tanggap terhadap apa yang wisatawan inginkan.

3. PT. Indonesia Air Asia disarankan untuk mempertahankan pelaksanaan yang telah dirasa puas oleh wisatawan seperti yang terdapat pada dimensi kualitas pelayanan yaitu, tangibles, reliability, dan empathy. Diharapkan juga bagi perusahaan menyediakan guest comment pada halam web air asia, dengan adanya guest comment perusahaan dapat mengetahui apa saja keluhan dari wisatawan dan perusahaan dapat dengan cepat memnerhaiki kesalahan dan menoerti ana

\section{DAFTAR PUSTAKA}

Harr, Lily. 2008. Service Dimensions of Service Quality Impacting Customer Satisfaction Of Fine Dining Restaurants In Singapore. Las Vegas: University of Nevada.

Rangkuti, Freddy. 2003. Measuring Customer Satisfaction. Jakarta: PT. Gramedia Pustaka Utama.

Suwantoro, Gamal. 1997. Dasar-dasar Pariwisata. Yogyakarta: Andi.

Yamit, Zulian. 2005. Manajemen Kualitas Produk dan Jasa. Jakarta: Ekonisia.

Tjiptono, Fandy. 2002. Strategi Pemasaran. Edisi pertama. Yogyakarta: Andi Offset. Tjiptono, Fandy. 2005. Pemasaran Jasa. Edisi Pertama. Malang: Bayumedia.

Majid, Suharto Abdul. 2009. Customer Service Dalam Bisnis Jasa Transportasi. Jakarta: Rajawali Pers.

Supranto. 2006. Pengukuran Tingkat Kepuasan Pelanggan Untuk Menaikkan Pangsa Pasar. Jakarta: Rineka Cipta. 